điện sinh lý của hội chứng ống cổ tay. 2010: 35-46.

6. Agee JM, Peimer CA, Pyrek JD. Endoscopic carpal tunnel release: a prospective study of complications and surgical experience. J Hand Surg; 1995;20A: 165-71.

7. Mallick A. Mbbs. Comparing the Outcome of a Carpal Tunnel Decompression at 2 Weeks and 6 Monthș.J Hand surg, 2007;32 A: 1154- 1158.

8. Nguyê̂n Văn Liệu. Nghiên cứu tác dụng phục hồi dẫn truyền dây thân kinh giữa của tiêm Depomedrol vào dây chằng vòng trong điều trị Hội chứng ống cổ tay. Y học thực hành, 2012;824(6): 47-49.

9. Nguyễn Văn Chương, Đồng Thị Thu Trang. Nghiên cứu đặc điểm lầm sàng, đo dẫn truyền và siêu âm dây thần kinh giữa ở bênh nhân có hội chứng ống cổ tay. Tạp chí Y- Dược học quân sự, 2012;37(8): 105-111.

\title{
KIẾN THỨC VỀ COVID-19 CỦA NHÂN VIÊN Y TẾ TUYẾN CO' SỞ TẠI HÀ NộI NĂM 2020
}

\section{Nguyễn Thị Minh Hiền*, Nguyễn Phương Hoa*}

\section{TÓM TẮT}

Kiến thức về COVID-19 của nhân viên y tế tuyến cơ sở góp phân quan trong trong viêc triển khai các biện pháp kiểm soát dịch bệnh, truyền thông tư vấn cho người dân trong cộng đồng. Nghiên cứu mô tả cắt ngang được tiến hành nhằm mô tả kiến thức về COVID-19 của nhân viên y tế tuyến cơ sở tại Hà Nội năm 2020. Có 675 nhân viên y tế tham gia vào nghiên cứu. Thông tin được thu thâp bằng bộ câuu hỏi tự điền. Kết quả nghiên cứu cho thẩy tuổi trung bình của NVYT là $38,8 \pm 9,2$. Có $34 \%$ nhân viên y tế trả lời đúng trên $90 \%$ câu hỏi về COVID-19. $64 \%$ trả lời đúng từ $70 \%$ $90 \%$, chỉ có $2 \%$ trả lời đúng dưới $70 \%$. Kiến thức triêu chứng nghi ngờ nhiễm COVID-19, thời điểm cần đeo khẩu trang, rửa tay có tỉ lệ đúng cao $(99,6 \%$, $99,9 \%$ và $99,7 \%$ ). Tỉ lệ có kiến thức đat (đúng $\geq 80 \%$ số câu) của NVYT là $84 \%$. Kết quả này cho thây các nhân viên y tế có kiến thức tương đối tốt về COVID19. Điều này góp phần rất quan trọng trong việc phòng chống và khống chế đai dich này ở Hà Nội.

Từ khóa: COVID-19, kiển thức, nhân viên y tế, tuyến y tế cơ sở

\section{SUMMARY \\ KNOWLEDGE ABOUT COVID-19 AMONG HEALTH STAFF AT GRASSROOTS LEVEL IN HANOI IN 2020}

Knowledge about COVID-19 among health staff at grassroots level makes an important contribution to implementing disease control measures and health education for people in the community. A crosssectional study was conducted. The study described the knowledge on COVID-19 among health staff at grassroots level in Hanoi, 2020. There were 675 health staff participate in the study. Information was collected using self-administered questionnaire. The results indicated that average age of heath staff was $38.8 \pm 9.2$. There were $34 \%$ of the staff gave the

*Trường Đại học Y Hà Nội

Chịu trách nhiệm chính: Nguyễn Thị Minh Hiền

Email: minhhien.r@gmail.com

Ngày nhận bài: 10.5.2021

Ngày phản biện khoa học: 25.6.2021

Ngày duyệt bài: 6.7.2021 correct answer for more than $90 \%$ of the questions about COVID-19; $64 \%$ answered correctly $70 \%$ to $90 \%$ of the questions and only $2 \%$ had less than $70 \%$ of the questions. Specifically, suspicious symptoms of COVID-19 and when to use face mask and wash hands were high correct answer rates (respectively $99.6 \%, 99.9 \%$ and $99.7 \%$ ). There were $84 \%$ of staff had acceptable rate of correct answers (equal or greater than $80 \%$ of the questions). The results showed that health staff had relatively good knowledge about COVID-19. This made a very important contribution to the prevention and control of the pandemic in Hanoi.

Keywords: COVID-19, knowledge, health staff, grassroots level

\section{I. ĐĂT VẤN ĐỀ}

COVID-19 là một dịch bệnh truyên nhiễm mới đăc biệt nguy hiểm lây từ người sang người với tốc độ nhanh với tác nhân là chủng virus corona mới (SARS-CoV-2) gây viêm đường hô hấp cấp tính. Bệnh lây truyền từ động vật sang người sau đó lây lan từ người sang người với tốc độ nhanh và đang diễn ra trên toàn câu. Khởi nguồn vào tháng 12 năm 2019 với tâm dịch đâu tiên được ghi nhận tại thành phố Vũ Hán (tỉnh Hồ Bắc, Trung Quốc). Ngày 11/3/2020, Tổ chức Y tế Thế giới (WHO) đã công bố COVID-19 là một đại dịch toàn câu [1]. Tính đến ngày 21/06/2021, đại dịch COVID-19 đã lan ra trên 200 quốc gia và vùng lãnh thổ với hơn 179 triệu người nhiếm và gân bốn triệu người tử vong. Riêng tại Việt Nam có hơn 13 nghìn ca nhiễm, trong đó có 5229 ca khỏi bệnh, 7959 ca đang được điều trị và 66 ca tử vong [2]. Bệnh hiện chưa có thuốc điều trị đặc hiệu nên chủ yếu là điêuu trị hỗ trợ và điêuu trị triệu chứng. Các biện pháp phòng bệnh chính là phát hiện sớm và cách ly ca bệnh.

Dịch COVID-19 diễn biến vố cùng phức tạp và khó lường, gây nhiêuu hậu quả nghiêm trọng, ảnh hưởng đến toàn bộ hệ thống y tế. COVID-19 làm quá tải nhiều hệ thống y tế ở nhiều quốc gia, 
ngay cả với các quốc gia phát triển do đặc điểm bệnh dễ lây lan và số lượng bệnh nhân không triệu chứng cao. Bên cạnh đó, COVID-19 gây tâm lý hoang mang cho người dân và nhân viên y tế (NVYT) trên toàn thế giới, đặc biệt ở những thời điểm dịch mới bùng phát khi kiến thức, thông tin về bệnh còn hạn chế. COVID-19 bùng phát kéo theo hậu quả lên toàn bộ đời sống kinh tế xã hội. Dịch bệnh làm tê liệt và suy giảm đà phát triển kinh tế toàn cầu, chủ yếu liên quan đến các biện pháp bắt buộc của chính phủ các nước để phòng chống dịch như: cách li, phong tỏa, han chế xuất nhập cảnh.... Các biện pháp này dẫn đến các hãng hàng không, du lịch, doanh nghiệp phải tạm đóng cửa, tình trạng thất nghiệp gia tăng, thiếu lương thực và bất ổn xã hội, thậm chí nhiêu thương hiệu tuyên bố phá sản.

Tính tới thời điểm hiện tại, Việt Nam là một trong những quốc gia thành công nhất trong việc phòng chống và điêuu trị bệnh COVID-19. Mặc dù có nhiêu bất lợi như: đường biên giới dài với Trung Quốc; hội nhập quốc tế sâu rộng; còn nhiều hạn chế về kinh tế, y tế; đặc điểm dân số đông... nhưng nhờ chiến lược đúng đắn, nước ta đã thu được nhiều thành cổng. Trong hệ thống y tế Việt Nam, tuyến y tế cơ sở (YTCS) bao gồm tuyến quận (huyện) và phường (xã) có vai trò hết sức quan trọng trong việc phòng chống các dịch bệnh truyền nhiễm như lao, cúm $\mathrm{A} / \mathrm{H} 1 \mathrm{~N} 1$, sởi... Trong dịch COVID-19, tuyến YTCS một lần nữa đã chứng minh vai trò vô cùng quan trọng và không thể thay thế qua các hoat động như: tuyên truyền kiến thức cho người dân; iây mẫu, bảo quản và vận chuyển bệnh phẩm; phòng chống lây nhiễm cho cán bộ y tế, hướng dẫn cách ly y tế tại nhà; báo cáo rà soát sức khỏe người về từ nước ngoài, vùng dịch; theo dõi y tế với các trường hợp cách ly tại nhà hàng ngày, báo cáo theo quy định...

Do đó, kiên thức về dịch COVID-19 của nhân viên y tế tại tuyến y tế cơ sở là hết sức quan trong để phát huy được tối đa vai trò và sự đóng góp của lực lượng y tế này trong việc phòng và khống chế dịch COVID-19 cũng như các dịch bệnh khác có thể xảy ra. Từ những lí do trên, nghiên cứu này được tiến hành với mục tiêu: Mố tả kiến thức về COVID-19 của nhân viên y tế tuyến cơ sở tại Hà Nội năm 2020.

\section{II. ĐỐl TƯỢNG VÀ PHƯƠNG PHÁP NGHIÊN CỨU}

2.1. Đối tượng nghiên cứu. Đối tượng nghiên cứu bao gồm: Bác sĩ, điều dưỡng, cử nhân y tế công cộng (YTCC), dược sĩ, kỹ thuật viên (KTV), y sĩ đang công tác tại trạm y tế xã/ phường và trung tâm y tế quận/huyện của Hà Nội

\section{2. Địa điểm và thời gian nghiển cứu}

- Địa điểm nghiên cứu: Nghiên cứu được tiến hành tại một số Trung tâm $Y$ tế thuộc Thành phố Hà Nội: Trung tâm Y tế huyện Ba Vì, Thanh Oai, Thanh Xuân, Ứng Hòa và Nam Từ Liêm

- Thời gian nghiên cứu: Tháng 4-5/2020. Đây là thời gian sau khi hết giãn cách xã hội của đợt dịch COVID-19 lần 1 tại Việt Nam.

\subsection{Phương pháp nghiên cứu}

Thiết kế nghiên cứu: Mộ tả cắt ngang

Cỡ mẫu nghiên cứu: Áp dụng công thức tính cõ mẫu cho nghiên cứu mô tả để xác định một tỷ lệ.

n: cõ̃ mẫu

$$
n=\quad Z^{2}(1-a / 2) \frac{p(1-p)}{(\varepsilon p)^{2}}
$$

a : Mức ý nghĩa thống kê (Chọn $\alpha=0,05 \rightarrow$ $\left.Z_{1-\alpha / 2}=1,96\right)$

\&: Khoảng sai lệch tương đối giữa mẫu nghiên cứu và quần thể.

Chọn $\varepsilon=0,08$

p: Chưa có nghiên cứu nào làm tương tự, nên lấy $p=0,5$ cho tỷ lệ lớn nhất

Thay thế vào công thức ta có kết quả là 600 nhân viên y tế, thêm $10 \%$ dự phòng bỏ cuộc hoặc không hoàn thành bộ câu hỏi, cõ̃ mẫu sẽ là 660 nhân viên y tế. Thực tế nghiên cứu đã thu thập được thông tin của 675 nhân viên y tế.

Phương pháp thu thập số liệu: phiếu điều tra là bộ câu hỏi tự điền. Nhân viển y tế của các trung tẩm y tế, trạm y tế được phát phiếu điều tra, giải thích mục tiêu, cách hoàn thành phiếu (tự làm dựa vào kiến thức của cá nhân mình, không trao đổi với đồng nghiệp, điền đủ các câu, không bỏ sót câu,...). Các nhân viên được phát phiếu và tự hoàn thành phiếu điều tra trong các buổi họp/giao ban tại cơ sở y tế dưới sự giám sát của thành viên nhóm nghiên cứu.

Phương pháp phân tích và xử lí số liệu: Các số liệu được làm sạch, mã hóa, phân tích bằng phần mềm SPSS 22.0, thống kê mô tả tần số, tần suất, tỷ lệ phần trăm, giá trị trung bình, độ lệch chuẩn (SD).

Các thuật toán thống kê trong y học phù hợp với các chỉ số và biến số khác nhau: Test ChiSquare $(x 2)$ được sử dụng để so sánh các tỷ lệ (Fisher's exact test được sứ dụng thay thế khi có giá trị kì vọng $<5$ ).

Phân loại kiến thức đạt khi trả lời đúng từ $80 \%$ trở lên $(\geq 80 \%)$ trong số 18 câu hỏi về kiến thức COVID-19.

Đạo đức nghiên cứu: Nghiên cứu này chỉ sử dụng phương pháp thu thập số liệu thông 
qua bộ câu hỏi thiết kế sẵn nên không gây tác hại cho các đối tượng tham gia nghiên cứu. Các đối tượng tham gia nghiên cứu được giải thích về mục đích điều tra, nội dung thông tin thu thập, tự nguyện đồng ý tham gia, được giữ bí mật và số liệu được sử dụng cho mục đích nghiên cứu.

\section{KẾT QUẢ NGHIÊN CứU}

3.1. Đặc điểm chung của đôi tượng nghiên cứu

Bảng 3.1. Một số đặc điểm chung của đôi tượng nghiên cứu

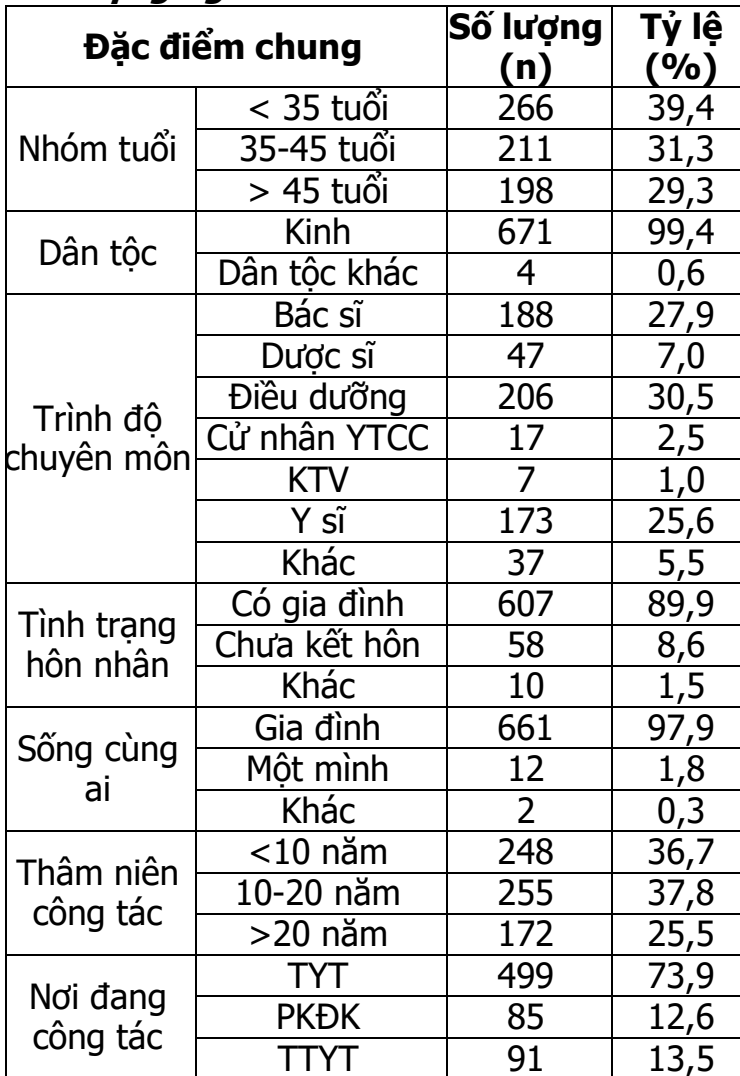

Tuối trung bình ( \pm SD) năm: 38,8 $\pm 9,2$

Thâm niên công tác $\pm S D$ ) năm : 13,8 $\pm 8,7$

Độ tuổi trung bình của NVYT tham gia nghiên cứu này là $38,8 \pm 9,2$, người trẻ nhất 23 tuổi và người cao tuối nhất 60 tuổi, trong đó nhóm tuổi dưới 35 chiếm tỉ lệ cao nhất là 39,4\%.

Thâm niên công tác trung bình là $13,8 \pm 8,7$, ít nhất là 1 năm và nhiều nhất là 38 năm công tác.

Trong tổng số NVYT, 30,5\% là điều dưỡng, tiếp theo là bác sĩ chiếm $28 \%$ và y sĩ chiếm $25,6 \%$.

Các NVYT công tác tại các trạm y tế chiếm tì lệ cao nhất $(73,9 \%)$, có $13,5 \%$ NVYT công tác tại các trung tâm y tế và thấp nhất là $12,6 \%$ tại các phòng khám đa khoa.

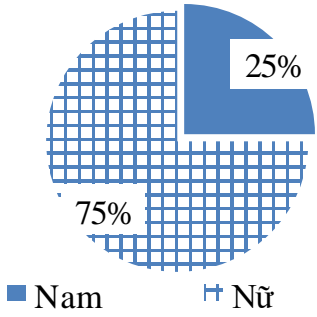

Biểu đồ 3.1. Phân bố đôi tượng nghiên cứu theo giới

Trong 675 NVYT tham gia nghiên cứu thì nữ giới chiếm tỉ lệ $75 \%$, nhiều hơn số NVYT là nam giới (chỉ chiếm 25\%).

3.2. Kiến thức về COVID-19 của nhân viên y tế

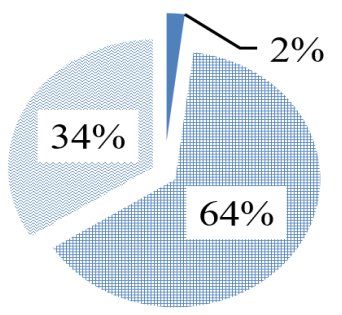

$-<70 \% \quad 70-90 \% \quad>90 \%$

\section{Biểu đồ 3.2. Mức độ kiến thức chung của} nhân viên y tế

NVYT trả lời đúng từ $70-90 \%$ số câu hỏi chiếm tỉ lệ cao nhất là $64 \%$, trả lời đúng trên $90 \%$ chiếm 34\%, thấp nhất là nhóm trả lời đúng dưới $70 \%$ với $2 \%$ tổng số nhân viên y tế.

Bảng 3.2. Kiến thức đúng về COVID-19

\begin{tabular}{|c|c|c|}
\hline Nội dung & $\begin{array}{c}\text { Số lượng } \\
\text { (n) }\end{array}$ & $\begin{array}{l}\text { Tỷ lế } \\
(\%)\end{array}$ \\
\hline Phân loại bệnh COVID-19 & 671 & 99,4 \\
\hline Đường lây truyền COVID-19 & 658 & 97,5 \\
\hline $\begin{array}{c}\text { Virus Corona tồn tại bao lâu } \\
\text { trong không khí }\end{array}$ & 229 & 33,9 \\
\hline $\begin{array}{l}\text { Virus Corona tồn tai trên bề } \\
\text { mặt nào lâu nhất }\end{array}$ & 386 & 57,2 \\
\hline $\begin{array}{c}\text { Virus corona tồn tại trong môi } \\
\text { trường nào lấu hơn }\end{array}$ & 635 & 94,1 \\
\hline $\begin{array}{l}\text { Khoảng cách an toàn với người } \\
\text { xung quanh }\end{array}$ & 631 & 93,5 \\
\hline $\begin{array}{l}\text { Đối tượng nào có thể bị nhiểm } \\
\text { COVID-19 }\end{array}$ & 668 & 99,0 \\
\hline Nhiêm và phát bệnh COVID-19 & 501 & 74,2 \\
\hline $\begin{array}{l}\text { Đối tượng khi mắc COVID-19 có } \\
\text { nguy cơ diến biến nặng }\end{array}$ & 617 & 91,4 \\
\hline $\begin{array}{l}\text { Triệu chứng nghi ngờ mắc } \\
\text { COVID-19 }\end{array}$ & 672 & 99,6 \\
\hline Thời gian ủ bệnh của COVID-19 & 633 & 93,8 \\
\hline $\begin{array}{l}\text { Xét nghiêm nào hiệu quả nhất } \\
\text { trong chẩn đoán COVID-19 }\end{array}$ & 656 & 97,2 \\
\hline
\end{tabular}




\begin{tabular}{|c|c|c|}
\hline $\begin{array}{c}\text { Hiê̂n nay có vacxin phòng } \\
\text { bệnh COVID-19 chưa }\end{array}$ & 631 & 93,5 \\
\hline $\begin{array}{c}\text { Đeo khấu trang đế bảo vệ } \\
\text { đối tượng nào }\end{array}$ & 523 & 77,5 \\
\hline Khi nào cần đeo khấu trang & 674 & 99,9 \\
\hline Khi nào cần rửa tay & 673 & 99,7 \\
\hline $\begin{array}{c}\text { Rưa tay đúng cách gồm bao } \\
\text { nhiêu bước }\end{array}$ & 657 & 97,3 \\
\hline Thời gian rưa tay & 571 & 84,6 \\
\hline
\end{tabular}

NVYT có tỉ lệ trả lời đúng về COVID-19 tương đối cao, các kiến thức có tỉ lệ đúng cao là: thời điểm cần đeo khẩu trang đúng 99,9\%, thời điểm cần rửa tay đúng $99,7 \%$, các triệu chứng nghi ngờ bị mắc COVID-19 đúng 99,6\%.

Các kiến thức về thời gian tồn tại của virus Corona trong không khí và trên bề mặt nào lâu nhất có tỉ lệ đúng thấp nhất lần lượt là: 33,9\% và $57,2 \%$. Có $4 / 18$ câu hỏi có tỉ lệ trả lời đúng dưới 80\%, 13/18 câu hỏi có tỉ lệ trả lời đúng trên 90\%

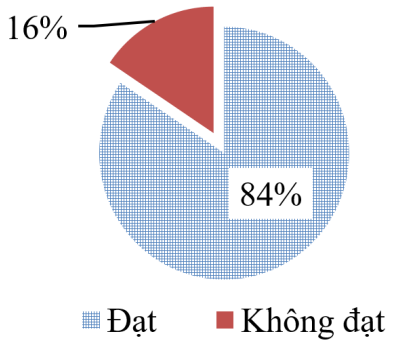

Biểu đồ 3.3. Tỉ lệ trả lời đạt (đúng $\geq 80 \%$ số câu) của NVYT

Nghiên cứu cho thấy có $84 \%$ số NVYT có mức độ kiến thức về COVID-19 là đạt. tỉ lệ kiến thức chưa đạt tương đối thấp, chỉ có $16 \%$.

Bảng 3.3. Tì lệ trá lời đạt theo một số đặc điểm

\begin{tabular}{|c|c|c|c|c|}
\hline $\begin{array}{c}\text { Đăc } \\
\text { điểm }\end{array}$ & $\begin{array}{c}\text { Sốn } \\
\text { lượng }\end{array}$ & $\begin{array}{c}\text { Tỷ lệ } \\
(\%)\end{array}$ & p \\
\hline \multirow{2}{*}{ Giới tính } & Nam & 143 & 84,6 & \multirow{2}{*}{0,668} \\
\cline { 2 - 4 } & Nữ & 421 & 83,2 & \\
\hline \multirow{2}{*}{$\begin{array}{c}\text { Nhóm } \\
\text { tuổi }\end{array}$} & $<35$ tuối & 224 & 84,2 & \\
\cline { 2 - 4 } & $35-45$ tuối & 177 & 83,9 & \multirow{2}{*}{0,853} \\
\cline { 2 - 4 } & $>45$ tuối & 163 & 82,3 & \\
\hline \multirow{2}{*}{$\begin{array}{c}\text { Thâm } \\
\text { niên } \\
\text { công tác }\end{array}$} & $<10$ năm & 205 & 82,7 & \\
\cline { 2 - 4 } & $10-20$ năm & 223 & 87,5 & \multirow{2}{*}{0,065} \\
\cline { 2 - 4 } & $>20$ năm & 136 & 79,1 & \\
\hline
\end{tabular}

Tỉ lệ trả lời đạt của NVYT nam $(84,6 \%)$ cao hơn so với các NVYTं nữ (83,2\%). Tuy nhiên, sự khác biệt này chưa có ý nghĩa thống kê $(p>0,05)$.

Tỉ lệ trả lời đạt của NVYT theo 3 nhóm tuổi < 35 tuối, từ 35-45 tuổi và > 45 tuổi lần lượt là $84,2 \%, 83,9 \%$ và $82,7 \%$, không có sự khác biệt về tỉ lệ này giữa 3 nhóm tuổi $(p>0,05)$.

Tỉ lệ trả lời đạt của NVYT có thâm niên công tác từ $10-20$ năm là cao nhất $87,5 \%$, thấp nhất là nhóm thâm niên trên 20 năm với 79,1\%, nhóm thâm niên dưới 10 năm đạt $82,7 \%$. Tuy nhiên, sự khác biệt này không có ý nghĩa thống kê $(p>0,05)$.

\section{BÀN LUẬN}

4.1. Đặc điểm chung của đối tượng nghiên cứu. Độ tuổi trung bình của các NVYT tại tuyến YTCS là 38,8 $\pm 9,2$, người trẻ nhất 23 tuổi và người lớn nhất 60 tuổi. Kết quả này cao hơn so với nghiên cứu tại Thành phố Hồ Chí Minh cho thây các NVYT có độ tuổi trung bình là 30,1 $\pm 6,1$ [3]. Một nghiên cứu tương tự tại Ả Rập có kết quả là: tuổi trung bình của các chuyên gia chăm sóc sức khỏe là 39,69 $\pm 8,48$ [4].

NVYT có thâm niên công tác trung bình là 13,8 năm, ít nhất là 1 năm và nhiều nhất là 38 năm công tác. Kết quả này cao hơn nhiều so với nghiên cứu tại thành phố Hồ Chí Minh là đa số NVYT có kinh nghiệm làm dưới 5 năm $(62,9 \%)$ [3] và nghiên cứu tại Bangladesh các NVYT có thâm niên trung bình là 4 năm [5].

Trong số 675 NVYT tham gia nghiên cứu thì nhân viên nữ chiếm $75 \%$ và nhân viên nam chiếm $25 \%$. Kết quả này tương tự với nghiên cứu tại tỉnh Đắc Lắc: $67,7 \%$ nũ , 32,3\% nam [6] và nghiên cứu tại Thành phố Hồ Chí Minh: 74\% nữ [3]. Một nghiên cứu khác thu thập phản hồi của NVYT trên toàn câuu trong tuần đầu tiên của tháng 3 năm 2020 qua bộ công cụ khảo sát trên web cho thấy có $51,6 \%$ là nhân viên nam, $48,3 \%$ là nũ̃ [7].

4.2. Kiến thức về COVID-19. Kết quả nghiên cứu cho thấy kiến thức về COVID-19 của các NVYT tại tuyến YTCS ở Thành phố Hà Nội tương đối cao. Có $34 \%$ số NVYT trả lời đúng trên $90 \%$ số câu hỏi, $84 \%$ nhân viên có điểm kiến thức đạt (trả lời đúng từ $80 \%$ số câu hỏi trở lên). Kết quả nghiên cứu của chúng tôi cũng tương tự như kết quả nghiên cứu tại Thành phố Hồ Chí Minh với $88,4 \%$ người tham gia có đủ kiến thức về COVID-19 [3].

Tỉ lệ kiến thức đạt của NVYT tại Hà Nội không có sự khác biệt giữa một số đặc điểm như giới tính, nhóm tuổi và thẩm niên công tác $(p>$ $0,05)$. Nghiên cứu tại Ả Rập cũng cho thấy không có sự khác biệt về điểm kiến thức giữ 2 nhóm nam và nữ [4]. Trong khi đó, nghiên cứu tại Đắc Lắc lại cho thấy có sự khác biệt đáng kể giữa nhân viên nam và nữ khi cho thấy nhân viên y tế là nữ có điểm kiến thức cao hơn so với nhân viên nam [6].

Các kiến thức có tỉ lệ đúng cao nhất là: thời điểm cần đeo khẩu trang đúng 99,9\%, thời điểm 
cần rửa tay đúng $99,7 \%$, các triệu chứng nghi ngờ mắc COVID-19 đúng 99,6\%. Tuy nhiên, các kiến thức về thời gian tôn tại của virus Corona trong không khí và trên bề mặt nào lâu nhất có tỉ lệ đúng còn thấp lần lượt là: $33,9 \%$ và $57,2 \%$.

Nghiên cứu thu thập số liệu ở đợt bùng phát dịch lần thứ nhất tại Việt Nam, trong đó Hà Nội có số ca lây nhiễm cao so với các tỉnh khác ở đợt này. Kết quả nghiên cứu cho thấy hầu hết NVYT đã cập nhật kiến thức về COVID-19 kịp thời, tác dụng của việc truyên thông của Bộ Y tế qua các buổi tập huẩn, tài liệu phát tay, qua các phương tiên thông tin đại chúng là có hiệu quả tốt nên kiến thức về COVID-19 của NVYT tại tuyến YTCS của Hà Nội khá cao. Kết quả nghiên cứu này cung cấp bằng chứng cho thấy đội ngũ NVYT cơ sở có sự chuẩn sẵn sàng về kiến thức cho công tác phòng chống đại dịch COVID-19 trong tình hình dịch bệnh vẫn còn đang căng thẳng hiện nay. Đây chính là một trong những lí do góp phần vào sự thành công của việc phòng chống dịch COVID-19 của thành phố Hà Nội nói riêng và của Việt Nam nói chung. Bên cạnh đó, vẫn còn một số kiến thức có tỉ lệ trả lời đúng tương đối thấp như: thời gian virus corona tồn tại trong không khí và trên bề mặt nào lâu nhất, vấn đề này cũng rất quan trọng trong việc phòng tránh lây nhiễm bệnh, vì vậy vẫn cần cung cấp thêm thông tin về những khía cạnh này của COVID-19 cho NVYT cơ sở để việc phòng tránh dịch bệnh đạt hiệu quả cao hơn nữa, vì đây là một "mắt xích" rất quan trọng - là tuyến đầu chống dịch với vai trò: truyền thông trong cộng đồng, truy vết phát hiện sớm ca nhiễm, quản lí các đối tượng nguy cơ tại cộng đồng.

\section{KẾT LUÂN}

- Độ tuổi trung bình của các NVYT tại tuyến cơ sở là 38,8 $\pm 9,2$, thâm niên công tác trung bình là 13,8 năm, nhân viên nữ chiếm $75 \%$

- Kiến thức về COVID-19 của nhân viên y tế tuyến cơ sở tại Hà Nội đạt tương đối cao. Có $64 \%$ số NVYT trả lời đúng được 70-90\% số câu hỏi về COVID-19. Tỷ lệ trả lời đúng trên $90 \%$ số câu hỏi đạt tỷ lệ là $34 \%$.

- Chưa thấy sự khác biệt về kiến thức COVID19 theo một số đặc điểm chung như giới tính, nhóm tuổi và thâm niên công tác.

\section{TÀI LIÊU THAM KHẢO}

1. WHO (2020). Director-General's opening remarks at the media briefing on COVID-19 - 11 March 2020, 21/06/2021.

2. Bô Y $\mathbf{Y}$ tế (2021). Trang tin về dich bệnh viêm đường hô hấp cấp COVID-19, <https:// ncov.moh.gov.vn/ >, 21/06/2021.

3. Huynh G, Nguyen T.N.H, Tran V.K et al (2020). Knowledge and attitude toward COVID-19 among healthcare workers at District 2 Hospital, Ho Chi Minh City. Asian Pac J Trop Med, 13, 52-58.

4. Mohammed Basheeruddin Asdaq S., A.S A., Imran Mohd. et al (2021). Knowledge, attitude and practices of healthcare professionals of Riyadh, Saudi Arabia towards covid-19: A crosssectional study. Saudi J Biol Sci, 15, 30-47.

5. Hossain M.A., Rashid M.U.B., Khan M.A.S. et al (2021). Healthcare Workers' Knowledge, Attitude, and Practice Regarding Personal Protective Equipment for the Prevention of COVID19. J Multidiscip Healthc, 14, 229-238.

6. Tien T.Q., Tuyet-Hanh T.T., Linh T.N.Q. et al (2021). Knowledge, Attitudes, and Practices Regarding COVID-19 prevention among Vietnamese Healthcare Workers in 2020. Health Serv Insights, 14, 34-40.

7. Bhagavathula A.S, Aldhaleei W.A, Rahmani J et al (2020). Knowledge and Perceptions of COVID-19 Among Health Care Workers: Cross-Sectional Study. JMIR Public Health Surveill, 6(2), e19160, 40-45.

8. Zhang $M$, Zhou $M$, Tang $F$ et al (2020). Knowledge, attitude, and practice regarding COVID-19 among healthcare workers in Henan, China. J Hosp Infect, 105(2), 183-187.

\section{KHẢO SÁT THỰC TRANG CHẤT LƯợNG GIẤC NGỦ Ở NGƯờI BÊNH TĂNG HUYẾT ÁP TẠI XÃ NAM PHONG, THÀNH PHỐ NAM ĐỊNH, NĂM 2019}

\section{TÓM TẮT}

\footnotetext{
*Trường Đại họ Điều dưỡng Nam Định Chịu trách nhiệm chính: Nguyễn Thị Huễ Email: huedhdd@gmail.com Ngày nhận bài: 6.5 .2021 Ngày phản biện khoa học: 24.6.2021 Ngày duyệt bài: 5.7.2021
}

\section{Nguyễn Thị Huế*, Đinh Thị Phương Hoa*}

Nghiên cứu mô tả cắt ngang nhằm mục tiêu mô tả thực trạng chất lượng giấc ngủ (CLGN) ở người bệnh tăng huyết áp tại xã Nam Phong, thành phố Nam Định năm 2019. Nghiên cứu sử dụng bộ công cụ đánh giá chất lượng giấc ngủ Pittsburgh Sleep Quality Index (PSQI) đã được dịch sang tiếng việt và được kiểm định lại độ tin cây trước khi thu thập số liệu chính thức. Phướng pháp chọn mẫu toàn bộ và phỏng vấn trực tiếp được áp dụng để thu thập số liệu trong nghiên cứu. Kết quả thu được có 49,3\% đối tượng cần 